\title{
Stimulating Understanding of Properties of Quadrilaterals Using Van Hiele's Model: A Lesson Study
}

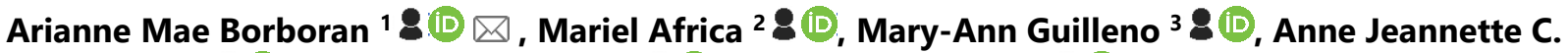 \\ Pamplona4 ${ }^{4}$ (D) Jennifer Torrefranca 5 \& (D) and Levi E. Elipane ${ }^{6} 8(\mathrm{D})$ \\ ${ }^{123456}$ College of Graduate Studies and Teacher Education Network, Philippine Normal University, Taft Avenue corner Ayala \\ Boulevard, City of Manila, Philippines \\ $\triangle$ Corresponding Author: Arianne Mae Borboran, E-mail: borboran.at@pnu.edu.ph
}

\section{ARTICLE INFORMATION}

Received: January 08, 2021

Accepted: March 02, 2021

Volume: 2

Issue: 1

DOI: 10.32996/jmss.2021.2.1.3

\section{KEYWORDS}

Van Hiele's Model, Geometry, lesson study, polygons, properties of quadrilaterals

\section{ABSTRACT}

This paper explores Van Hiele's Model's use in planning the tasks to identify the properties of quadrilaterals. Lesson study, a professional development program that enables teachers to collaborate to improve teaching and learning quality, was utilized to get necessary data needed for the study. The authors aimed to see to what extent Van Hiele's Model affects the students' engagement and development of knowledge in the learning of the research topic. Some observations during the research lesson were as follows: 1) retention of prior knowledge on quadrilaterals was little to nonevident to the students 2) most students still use jargons in order to describe the properties of quadrilaterals and 3) most students were not able to showcase skills in measuring lengths and angles in identifying properties of the quadrilaterals. Given these observations, the following recommendations were as follows: 1) continuous integration and use of mathematical tools such as ruler and protractor in teaching different concepts and processes in Mathematics 2) identifying the level of the learners' readiness based on the Van Hiele's model to provide appropriate examples and activities in the context of the students 3 ) providing hands-on activities such as geometric construction and measuring activities that would enhance students' capabilities in reasoning and proving. Lesson study served as a powerful tool to reflect on the researchers' processes and activities in conducting the study.

\section{Introduction}

The heart of the mathematics $\mathrm{K}$ to 12 frameworks in the Philippines is critical thinking and problem-solving skills. One of this premise's underlying goals is to improve the students' geometric thinking levels. Geometry, on the one hand, is one of the many branches of mathematics that hones the development of the students' creativity, perseverance and productivity and, on the other hand, offers a lot of activities for the teacher to reinforce cooperative learning - with this, it is regarded important in many scientific, technological and professional subjects (Al-ebous, 2016). However, despite the many opportunities that the area offers, learning any geometric concept and skills has been considered one of the most complex teaching and learning processes (Ulger \& Broutin, 2017).

There are different factors why learning and teaching geometry has been perceived as a complex area to ponder. One of these factors is the child's environment (Hansen \& Pratt). The students are very much exposed in different shapes with a horizontal base, and as a result, they tend to lose the figure's attributes when it is rotated or tilted. For example, the students could easily identify that a square is a square (with four equal sides and four right angles) when it is drawn horizontally. However, retaining the same shape but when drawn in a tilted position, they may call the figure in various names like a "diamond" or kite-- losing the properties that they know. Another factor is the large number of attributes that they have to consider in a figure (Hansen and Pratt). Students tend to memorize these properties (e.g. how many sides are there, the sum of interior angles, the number of diagonals). It might be aggravating for them to memorize these without knowing and understanding much how they got these properties at hand. Moreover, historically speaking, Geometry is one of the subjects in mathematics often skipped since most

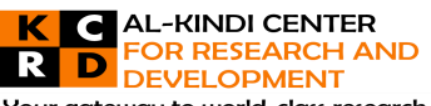

Your gateway to world-class research

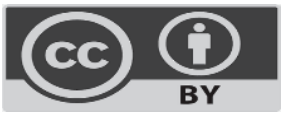

Published by Al-Kindi Center for Research and Development. Copyright (c) the author(s). This open access article is distributed under a Creative Commons Attribution (CC-BY) 4.0 license 
teachers are not comfortable teaching the underlying concepts or because it is not part of the basic standardized tests. (Van de Walle \& Lovin, 2006). But because of the continuous efforts made, the National Council of Teachers of Mathematics (NCTM) [5], have helped develop four content goals for geometry which could be summarized by these headings: 1 . Shapes and Properties 2. Transformation 3. Location and 4. Visualization.

However, in this paper, we specifically explored Van Hieles's Model's use in the engagement and understanding of the different properties of Quadrilaterals. In the Philippine curriculum, quadrilaterals are introduced already as early as in Pre-School to introduce the concept of similarities (e.g. same size, shape, color). This notch up when they proceed to grades 3 and 4 where they are learning how to get the area and perimeter and classifying quadrilaterals in accordance with their properties. Classification of quadrilaterals is very important. This guides them in solving different problems and further helps them in working with proofs once they will be in secondary schools already (Turnuklu, Akhas, \& Alayli).

\subsection{Designing Lesson in Classification of Quadrilaterals using Van Hiele's Model}

It is believed that experiences and continuous active exploration help students develop relationship from one concept to another. Thus, students must be given the chance to play around with their ideas for them to be able to discover more relationships (Van de Walle \& Lovin, 2006). This is one of the critical concepts that Pierre van Hiele and Dina van Hiele- Gelfdof thought of when they started working on the Van Hiele model. As both teachers for years in Netherlands, they researched Geometry's nature and reflected why the students have difficulty learning Geometry ( Susan, 2010). Their research was the Van Hiele's model which, until up today, is still widely used in teaching Geometrically concepts.

Van Hiele's model follows five hierarchical ways of understanding ideas and each of the following levels has its own attributes and characteristic. It should be noted that these levels are both sequential and hierarchical (Pusey, 2003).

The first level is Visualization. The students' activities focus more on classifying or sorting objects that look alike in the Visualization level. Therefore, on this level the students just need to focus more on the figure's appearance (Van de Walle \& Lovin, 2006). The second level is Analysis. The students could already identify properties of shapes and sort them into different classes on this level. However, though they could identify the figure's distinct attributes, they still do not know how to connect one attribute from another (Susan, 2010). The third level is Deduction, here the students could acknowledge the properties of the figures and realize its relationship from one property to another. They could already use if-then statements and give definitions to justify their arguments. The fourth level is Abstraction wherein the students already have a system of logic and may be able to construct proofs and use or justify axioms in geometry. Rigour's last level is where the students could already compare and contrast different axioms. Here, the students could also understand formal aspects of deduction.

Although it is constructed that some of the aspects in using Van Hiele's model is the acknowledgement of the existence of levels and highlighting that it is important for the students to progress from one level to another (Vojkuvkova, 2012) [9], inside a classroom different learner may have the same age classes but in varying levels of geometrical thinking. From this assumption, the researcher developed a lesson plan that caters all Van Hiele's model levels and promotes experiential and cooperative learning. The activities are as follows:

\subsection{Visualization}

The teacher will show varying pictures of polygons and non-polygons. The students' task is to sort these figures into varying group according to the "likeness" of the figures.

\subsection{Analysis}

The students will be divided into 5 groups. They will be given 5 different quadrilaterals: square, rectangles, parallelogram, trapezoid, rhombus. Their task is to describe each quadrilateral in any terms that they know.

\subsection{Deduction}

The students will be given another manila paper with a Venn diagram. The students will explore the similarities.

\subsection{Abstraction}

Ask the students several questions that may lead them to make theories about quadrilaterals. Ask them to give examples or counterexamples regarding the statements.

- Are squares, rectangles?

- Are rectangles, squares?

- Are squares, rhombus?

- Are rhombuses, squares? 


\subsection{Rigor}

Go back to the anchored task and let the students make a tree diagram about the relationship of the shapes.

\section{Objective of the Study}

This study was conducted to explore the students' engagement and understanding in classifying quadrilaterals using Van Hiele's model. It also serves as a way to develop a lesson plan that could help teachers design how to teach quadrilaterals progressively and inclusively.

\section{Methodology}

In order to explore the students' engagement and understanding in classifying quadrilaterals using Van Hiele's model, the group used lesson study to reflect on the activities planned.

\subsection{Lesson Study}

Lesson study is a professional development model or process that originated in Japan. It is cycle teachers and other people working on the same community of practice collaborate and work hand in hand to develop and improve lessons that will intersect goals for improving teaching and learning (Elipane, 2015). A unique characteristic of lesson study is that it gives the observers a glimpse of how student thinks as the students are still located in the natural setting where they have their formal education. The teacher's challenge is to plan out activities that promote collaboration amongst the students. In order to carry this out, the researchers followed some procedure in order to reach this goal. The processes are as follows: 1. planning the research lesson 2. developing the lesson plan 3. implementing the lesson and 4. reflecting on the lesson's outcomes.

\section{A. Planning the research lesson}

In planning the research lesson, some factors must be considered in identifying and setting your goals to be aimed, like working out on what topic would be most relevant and amiable for the students right now. This research lesson took place during the second semester of the school year, where the students had already started working on Geometry concepts. From this lens, we were able to identify Quadrilaterals as our research lesson's topic. As mentioned above, identifying relationship in quadrilaterals is deemed important as they will be using this until they reach secondary schools (Turnuklu, Akkas, Alayli) ${ }^{[6]}$.

\section{B. Developing the Lesson Plan}

We used the Van Hiele model as a reference to formulating the activities planned for the Research Lesson. Van Hiele's model is widely used to work out with Geometry topics. In line with this, in developing the lesson plan, we considered having diverse learners. As such, all the Van Hiele's model levels were integrated in the lesson plan to cater to the students with varying levels.

\section{Implementing the Lesson}

The research lesson was conducted to 17 Grade 4 students of School of Everlasting Pearl, Inc. The lesson started with a review of the concept of Polygons. The task of the students' is to sort what figures are considered to be Polygons and what is not according to the definition that they remembered. This activity served as a way to review their past lesson and serve as a preparation for the next activities. Afterwards, the students were given quadrilateral cutouts for students to observe and describe. The next activities were about making relationships out of the observations that they have made.

\section{Results and Findings}

After implementing the research lesson we had a post-conference about significant observations and further recommendations to improve the lesson. However, to better understand the recommendations' prompt, we would establish first the different cultures that we have observed from the students.

\subsection{Retention of the prior knowledge was little to non-evident to the students.}

It has been a protruding fact that teaching and learning Geometry concepts still a challenging aspect of the Philippine curriculum. In the research lesson that was conducted, the minimum prior knowledge needed to make relationships and observations about quadrilaterals is identifying the kinds of angles and knowing how to use the ruler and

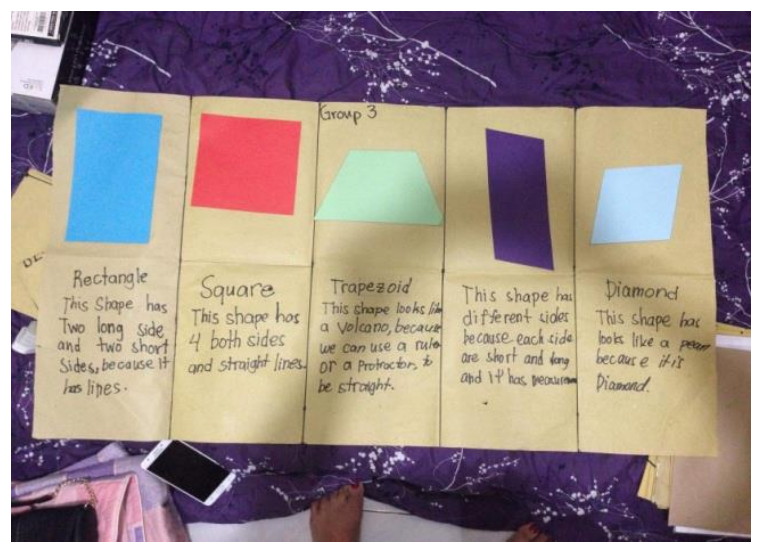
protractor. However, while having their group activity about describing the figures given to them, the teacher noticed that almost all groups were not using their rulers and protractors (materials that were prepared beforehand for them). When the students were asked why they were not using them, the students argued, "Ginagamit lang naman ang ruler para magdrawing ng straight lines at yung protractor para sa curved lines." (We only use rulers to draw straight lines and protractors for curved lines). This suggests that the students were novice when it comes to using mathematical tools when measurements plays a vital role in 
the development of our spatial environment (Battista, 2007, Jones and Tzekaki, 2016) [11][12]. Moreover, one group put into the description of trapezoids that, "Sigurado ako triangle to, hinati lang." (I am pretty sure that this is a triangle, it just so happened that the other parts were cut off).

\subsection{Most students still use jargons in order to describe figures.}

Still, in describing the quadrilaterals, it was evident for the students that they still describe the figures using their own context. Instead of citing mathematical concepts like congruency, parallelism or perpendicularity, or classifying the kinds of angles in a figure - the students used phrases as the figure looks like a table, a tent or a volcano.

This may suggest that the student has not reached the level yet where they could relate concepts in order to formulate new ones. However, this also shows that these students are rich in experiences that they bring inside the classroom. It is a challenge, though, on the teacher's part on how these experiences should be catered in order to help the students go from one level to another.

With these observations, the group was able to conclude three factors that may be able to help teachers in the continuing improvement in teaching Geometry: 1. continuous integration and use of mathematical tools in teaching 2 . identifying the level of the learners to provide examples in the context of the students and 3. providing activities that would enhance students' capabilities in reasoning and proving.

\subsection{Continuous integration and use of mathematical tools in teaching}

Using mathematical tools in Geometry and in any branch of mathematics is a way to enforce discovery learning and cooperative learning. In a modern era where there are already a lot of developed manipulative and software, it was interesting to see that some students find it illogical to use rulers and protractors-the basic instrument for measurement-to describe the sides and angles of a figure. In line with this, we highly recommend the continuous integration and use of these mathematical tools in teaching. Thus, the promotion of interconnectedness of the branches of Mathematics could also be one thing that we may consider. For example, when teaching addition, one may use the measurement of similar objects and determine the total length. These activities would enhance not only geometrical skills but also their arithmetic skills.

\subsection{Identifying the level of the learners to provide examples in the context of the students}

Van Hiele's model is one of the most prominent models used in teaching Geometry. This model is characterized by having sequential levels where age levels are not affected by age. Another is that the students' geometric experience is the most important factor for the students to move from one level to another and that the students should be given instructions that are of the same level as the students. It is really important to identify the children's level with these characteristics. As with the research lesson that we have conducted, we were not able to genuinely assess each of the students' ability. We know the only data is the students' Grade Level and what topics are they working on before we conducted the students. At the start of the research lesson, the students were not able to identify the definition of a parallelogram; but, they were able to separate the parallelograms and the non-parallelograms correctly. They also had a challenging time using the protractors and rulers since they were not used to using these tools to measure lines and angles--these became challenges for us during the research lesson.

\subsection{Providing activities that would enhance students' capabilities in reasoning and proving}

In any classroom, students have different levels and sometimes, these levels may change from one topic to another. A student might be in Level 3 already in the concept of quadrilateral but could be Level 1 in working with circles. With this premise, it is very important to have varied activities to cater the students' needs. During the research lesson, we may have some encounters where students have had a challenging time in working; however, since the activities were based on the different levels, the varying activities helped the students still be inclined to finish their tasks.

In preparing the lesson, it is also important that we design the students to help the students move from one level to another. Moreover, we also have to design the lesson so that the activities would be able to improve their way of reasoning and proving. These two skills, in any topic, are very important but oddly, are the two skills that are often left behind. The students should be skilled in finding relationship and connections and making criticisms and generalizations. These skills are not to be taught but skills to be realized upon. A teacher's role here is to plan and facilitate the activities that the students will be immersed in.

\section{Concluding Remarks}

It can be noted that Van Hiele's model is a powerful strategy to plan and carry out lessons in understanding the properties of Quadrilaterals as it helps various learners to improve from one level to another. However, belt of factors needs to be considered to make this lesson impactful. One factor is to know the students' schema and behaviour. Since the students mainly carry out the lesson, it is important to plan the activities based on the predicted actions that the students will have. The activities should not be too challenging for them as this may cause more confusion; likewise, the activities should not be too easy to the point that they will get bored. Another factor would be the teacher who acts as a learning facilitator. Now, to facilitate well the activities 
planned, it is important to ask the right questions to help the students find the right direction to unlock the key concepts needed.

It could also be concluded that planning the students' lessons and tasks beforehand is very crucial. The research group only gave a task at the end of the lesson to sort and produce a tree diagram of quadrilaterals -in line with this, all the reviews and tasks that were previously done before the group activity would be of help to the students in solving the anchored task. It was planned in such a way that it is not too leading for the students to be convened in only one method in solving the problem nor too disconnected that the students may not be able to see any connections from the activities made and the tasks to be done.

\section{Recommendations}

Additional insights were gained after the completion of the research lesson. These are the recommendations centered on the appraisals brought about by the study:

\subsection{Mathematical Shift}

It was seen that the students have had a challenging time using different mathematical tools to complete the activities planned. Although the topic is all about the Properties of Quadrilaterals, it could be noted that shifting from this topic to reviewing the process of using rulers and protractors, if needed and if it would be beneficial to understand the upcoming topics would be fine.

\section{2. Chunking of the Activities}

Due to time constraint, the group was given an hour to present the research lesson. Although the activities were carried out, the teacher could have processed the inputs of the students more for a better and more meaningful learning. With this, chunking the activities would be prescribed to have more time to process inputs.

\section{References}

[1] Al-ebous, T. (2016). Effects of the Van Hiele Model in Geometric Concepts Acquisition: The Attitudes towards Geometry and Learning Transfer Effect of the First Three Grades Students in Jordan. International Education Studies, 9(4)

[2] Ulger, T. K., \& Broutin, M. S. (2017). Pre- Service Mathematics Teachers' Understanding of Quadrilaterals and the Interval Relationships between Quadrilaterals: The Case of Parallelograms. European Journal of Educational Research , 6(3).

[3] Hansen, A., \& Pratt, D. (n.d.). How do we provide tasks for children to explore the definitions of quadrilaterals?

[4] Walle, J. A., \& Lovin, L. H. (2006). Teaching Student-Centered Mathematics (Grades 3-5). Pearson Education, Inc

[5] Turnuklu, E., Akkas, E. N., \& Alayli, F. G. (n.d.). Mathematics Teachers' Perceptions of Quadrilaterals and Understanding the Inclusion Relations.

[6] Susan, C. (2010). The Impact of Van Hiele based Geometry Instruction on Student Understanding. Mathematical and Computing Science Masters Paper 97.

[7] Pusey, E. L. (2003). The Van Hiele Model of Reasoning in Geometry: A literature review.

[8] Elipane, L. E. (n.d.). Integrating the essential elements of lesson study in pre-service mathematics teacher education.

[9] Vojkuvkova. (2012). The Van Hiele Model of Geometric Thinking. 72-75.

[10] Battista, M.T. (2007). The development of geometric and spatial thinking. In F.K. Lester (ed.) Second handbook of research on mathematics teaching and learning (pp. 843-908) Charlotte, NC

[11] Jones, K \& Tzekaki, M. (2016). Research on the teaching and learning of geometry. Second Handbook of Research on the Psychology of Mathematics Education: The Journey Continues. (pp. 109-149) Notterdam : Sense 